Jun Sugimoto • Toshihiro Yamauchi

Toyomasa Hatakeyama • Masaharu Isobe

\title{
Isolation and mapping of a polymorphic CA repeat sequence at the human VRK1 locus
}

Received: October 8, 1998 / Accepted: October 16, 1998

\begin{abstract}
VRK1 is a novel human putative serine/threonine kinase, and is located on chromosome 14 at band q32 where an autosomal recessive congenital microphthalmia (CMIC) is mapped. We isolated a polymorphic dinucleotide CA repeat marker from a genomic clone containing the human $V R K 1$ gene. This polymorphism will be useful in genetic studies of disorders localized at the $14 \mathrm{q} 32$ region, such as CMIC.
\end{abstract}

Key words CA repeat $\cdot V R K 1$ gene $\cdot$ Congenital microphthalmia (CMIC)

\section{Introduction}

The human VRK1 gene, isolated by Nezu et al. (1997), had $40 \%$ sequence identity with the B1R serine/threonine protein kinase of vaccinia virus, and was located between the markers D14S987 and D14S267 where the CMIC candidate gene is predicted to lie (Bessant et al. 1998). To study the relationship between genetic variation at the VRK1 locus and the genetic backgrounds of congenital microphthalmia, we isolated and characterized a dinucleotide repeat polymorphism at this locus.

\section{Source and isolation of CA repeat sequence}

A human genomic clone containing the VRK1 gene was identified from a bacterial artificial chromosome (BAC) library (Research Genetics Huntsville, AL, USA) by polymerase chain reaction (PCR) three-dimensional screening, using primer sequences derived from the $3^{\prime}$ portion of the

J. Sugimoto $\cdot$ T. Yamauchi $\cdot$ T. Hatakeyama $\cdot$ M. Isobe $(\triangle)$ Molecular and Cellular Biology Laboratory, Department of Materials and Biosystem Engineering, Faculty of Engineering, Toyama University, 3160 Gofuku, Toyama City 930-8555, Japan Tel. +81-764-45-6872; Fax +81-764-45-6874

e-mail: isobe@ ng.toyama-u.ac.jp gene. A fragment containing a CA repeat, identified by Southern blot hybridization of a BAC DNA digested by Sau3A1 with a $(\mathrm{CA})_{20}$ probe, was subcloned and sequenced. The infrared fluorescence image of the CA repeat is shown in Fig. 1. PCR primers were designed to flank this new repeat sequence for polymorphism analysis.

PCR primers

The PCR primers used were, forward (130E12 191S) 5'-GATGAAAAAGGTCTGCCAAGT-3', and reverse (130E12 496AS) 5'-GAAAGCTTCTGGATGGTAAAC$3^{\prime}$.

PCR conditions

PCR was performed in a volume of $10 \mu$ l containing $50 \mathrm{ng}$ genomic DNA, $10 \mathrm{mM}$ Tris- $\mathrm{HCl}(\mathrm{pH} 8.3), 10 \mathrm{mM} \mathrm{KCl}$, $3.75 \mathrm{mM} \mathrm{MgCl}_{2}, 1.25 \mathrm{mM}$ each of dNTPs, 2 pmol of an infrared fluorescence labeled forward primer, $2 \mathrm{pmol}$ of nonfluorescence reverse primer, and $0.25 \mathrm{U}$ of Taq polymerase. The cycle conditions were $95^{\circ} \mathrm{C}$ for $1 \mathrm{~min}$, then 20 cycles of $95^{\circ} \mathrm{C}$ for $40 \mathrm{~s}, 58^{\circ} \mathrm{C}$ for $1 \mathrm{~min}$, and $72^{\circ} \mathrm{C}$ for $2 \mathrm{~min}$, with a final extension step of $4 \mathrm{~min}$ at $72^{\circ} \mathrm{C}$, in an Omni Gene thermal cycler (Hybaid, Middlesex, England). The PCR products were electrophoresed in 0.25 -mm-thick denaturing $4 \%$ polyacrylamide gels at $2000 \mathrm{~V}$ for $2-4 \mathrm{~h}$, using an automated DNA sequencing machine, (IR4000; LI-COR, Lincoln, NE, USA). The sizes of alleles were determined by comparison with a sequencing ladder of a control plasmid.

\section{Polymorphism and allele frequency}

Five alleles were detected in 134 chromosomes of DNA from a Centre d'Etude du Polymorphisme Humain (CEPH) family. A representative infrared fluorescence image of the CA repeat polymorphism is shown in Fig. 1. The observed heterozygosity was 0.64 . The sizes and frequencies of the 
A

\section{Alelles}

$\begin{array}{llllllllll}5 & 4 & 6 & 4 & 4 & 5 & 5 & 3 & 5\end{array}$

$\begin{array}{lllllllll}3 & 3 & 5 & 3 & 3 & 3 & 3 & 3 & 3\end{array}$

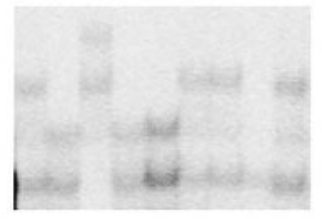

B

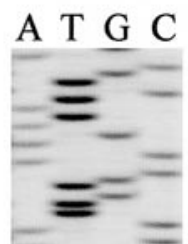

7

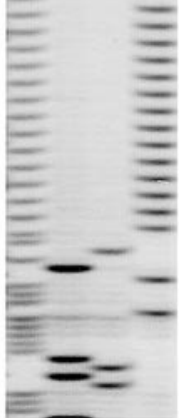

$(\mathrm{CA})_{16}$

mapping panel of 83 hybrid cell lines of the Stanford Human Genome Center (Boenke et al. 1991), by linkage to a marker AFMb323ye9 with a logarithm of differences (LOD) score of 6.46 .

Acknowledgements This work was supported in part by a Grant-in Aid from the Ministry of Education, Science, Sports, and Culture of Japan and by a Grant from the Human Frontier Science Program.

Table 1 Sizes and frequencies of the alleles of the CA repeat polymorphism in the VRK1 locus

\begin{tabular}{lll}
\hline Allele & Size (bp) & Frequency \\
\hline A1 & 324 & 0.08 \\
A2 & 326 & 0.61 \\
A3 & 328 & 0.02 \\
A4 & 330 & 0.22 \\
A5 & 332 & 0.07 \\
\hline
\end{tabular}

Fig. 1A Infrared fluorescence image showing a polymorphic CA repeat at the VRK1 locus in nine unrelated individuals. B Nucleotide sequence of the CA repeat at the VRK1 locus and the flanking regions

five alleles are shown in Table 1.

Mendelian inheritance. Codominant inheritance was observed in two three-generation families.

Chromosomal localization. The human VRK1 gene was assigned to human chromosome 14q32.1 (Nezu et al. 1997)

Radiation hybrid mapping. The newly isolated CA repeat at the VRK1 locus was mapped to 14q32.1, using the G3 RH

\section{References}

Bessant DA, Khaliq S, Hameed A, Anwar K, Mehdi SQ, Payne AM, Bhattacharya SS (1998) A locus for autosomal recessive congenital microphthalmia maps to chromosome 14q32. Am J Hum Genet 62: 1113-1116

Boehnke M, Lang K, Cox DR (1991) Statistical methods for multipoint radiation mapping. Am J Hum Genet 49: 1174-1188

Nezu J, Oku A, Jones MH, Shimane M (1997) Identification of two novel human putative serine/threonine kinases, VRK1 and VRK2, with structural similarity to vaccinia virus B1R kinase. Genomics 45: $327-331$ 